\title{
Oxygen consumption of rats with broad intestinal resection
}

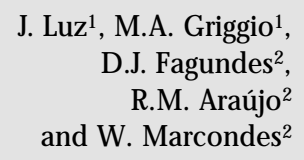

\begin{abstract}
${ }^{1}$ Disciplina de Fisiologia Renal e Termometabologia, Departamento de Fisiologia, and ${ }^{2}$ Disciplina de Técnica O peratória e Cirurgia Experimental, Departamento de Cirurgia, Escola Paulista de Medicina, Universidade Federal de São Paulo, São Paulo, SP, Brasil
\end{abstract}

\section{Correspondence \\ J. Luz \\ Disciplina de Fisiologia Renal e \\ Termometabologia \\ Departamento de Fisiologia \\ EPM, UNIFESP \\ Rua Botucatu, 862, 5 - andar \\ 04023-900 São Paulo, SP \\ Brasil \\ Fax: +55-11-575-9165 \\ E-mail: jluz@ ecb.epm.br \\ Research supported by FAPESP.}

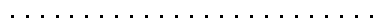

Received July 30, 1999

Accepted October 4, 2000

\section{Abstract}

The study was performed to investigate possible alterations in oxygen consumption in an animal model with broad intestinal resection. Oxygen consumption and the thermal effect of a short meal were measured in rats subjected to short bowel syndrome. Four groups of rats were used. Group I was the control group, group II was sham operated, group III was submitted to $80 \%$ jejunum-ileum resection, and group IV was submitted to $80 \%$ jejunum-ileum resection with colon interposition. Ninety days after surgery, oxygen consumption was measured over a period of $6 \mathrm{~h}$ with the animals fasted overnight. The thermal effect of feeding was determined in another session of oxygen consumption measurement in animals fasted for $12 \mathrm{~h}$. A 12kcal meal was then introduced into the animal chamber and oxygen consumption was measured for a further $4 \mathrm{~h}$. No differences in fasting oxygen consumption or in the thermal effect of the meal were detected among the groups studied. It is concluded that short bowel syndrome does not affect the overall energy expenditure of rats.

The small intestine alone is responsible for almost the whole intestinal absorption and resection of more than $50 \%$ of its length may cause nutritional and metabolic abnormalities known as short bowel syndrome which leads to body weight loss, malabsorption, steatorrhea and acid diarrhea (1). Since the clinical treatment of short bowel syndrome is expensive and associated with high morbidity and mortality, the interest in surgical procedures is increasing (2). Surgical treatment of the disease has the objective of controlling gastric hyperacidity, increasing the absorption area and intestinal transit time. Transit time can be increased by intestinal valve construction, antiperistaltic segment placement, and colon segment interposition (3-5).
Colon interposition is a surgical procedure that has proved to be technically feasible and may be useful for patients suffering from short bowel syndrome (2). The interposed colonic loop adapts itself to the functions of the small bowel increasing the absorptive surface area and leading to better absorption of the main nutrients $(6,7)$. The transit time is also increased (3).

The gastrointestinal tract has a metabolic activity which represents about $20 \%$ of whole body energy metabolism $(8,9)$. Since there is no information about the energy expenditure in individuals suffering from small bowel syndrome it may be relevant to study possible alterations in oxygen consumption in an animal model subjected to broad intestinal resection. 
Forty Wistar EPM-1 female rats were used at 3 months of age, with body weight between 180 and $220 \mathrm{~g}$. The animals, except for group I, were anesthetized intraperitoneally with sodium pentobarbital at a dose of $40 \mathrm{mg} / \mathrm{kg}$ body weight and assigned to four experimental groups:

Group I (control). No procedures were performed.

Group II (sham). The animals were subjected to laparotomy and to enterotomy in the midpoint of the small bowel using the same techniques as those used in the anastomoses for the other two groups.

Group III (resection). The animals were subjected to $80 \%$ resection of the jejunumileum, keeping $10 \%$ jejunum and $10 \%$ ileum. An end-to-end anastomosis was performed with the remnant ends.

Group IV (interposition). The same as group III, but with interposition of $3 \mathrm{~cm}$ of a pediculated distal colon segment with an isoperistaltic anastomosis with the remnant small bowel end and an end-to-end coloncolonic anastomosis.

The animals were observed for 90 days

Figure 1 - Minimum (upper panel) and average (lower panel) oxygen consumption in the four groups of rats, measured 90 days after the surgical procedures. There were no significant differences among them by ANOVA.

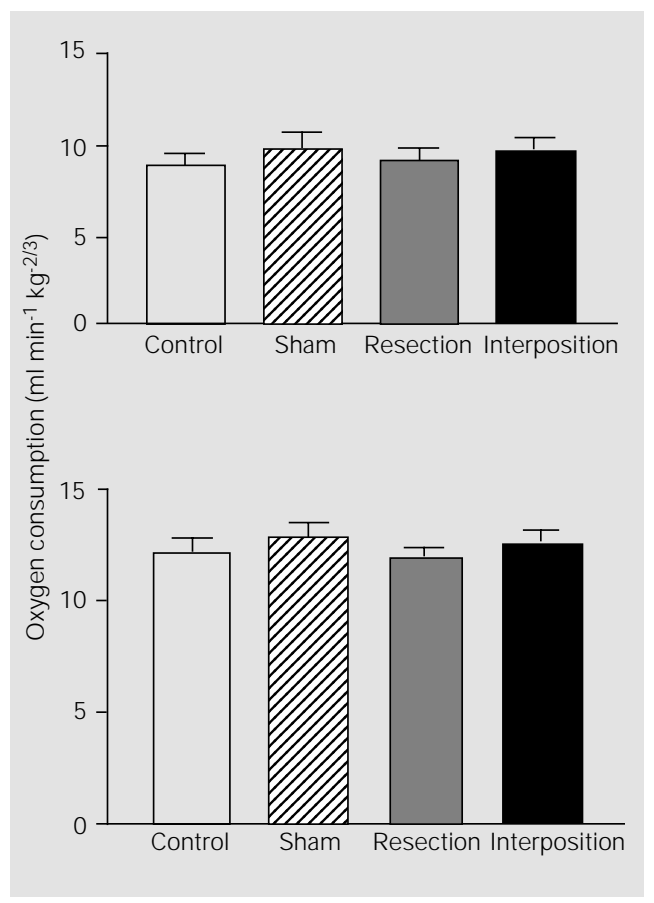

after surgery and then subjected to oxygen consumption measurements.

Oxygen consumption was measured in an open flow system consisting of five sealed chambers with a volume of 51 each, ventilated with a known flow of $2.0 \mathrm{l} / \mathrm{min}$ of room air by positive pressure. A sample of $0.5 \mathrm{ml} /$ min was drawn to an oxygen sensor (Sensor Medics Corp., Anaheim, CA, USA). The first cage remained empty and served as a baseline of room air recording. Electromagnetic valves allowed the measurement of one cage at a time. Oxygen concentration was recorded for $6 \mathrm{~min}$ in each cage so that 2 recording periods were obtained per cage per hour. Percent oxygen consumption was calculated from the difference measured between the baseline and the actual recording. Oxygen consumption $(\mathrm{ml} / \mathrm{min})$ was calculated from the percent oxygen consumption and the flow to the chambers, normalized to STPD (standard temperature and pressure, dry). The recording was performed for $6 \mathrm{~h}$, allowing the calculation of average oxygen consumption and minimum oxygen consumption. The values are expressed as $\mathrm{ml}$ $\min ^{-1} \mathrm{~kg}^{-2 / 3}$. Before the measurements the animals were subjected to a 12-h fast.

The cephalic thermal effect of food was measured by the same method as above. Oxygen consumption was measured for $1 \mathrm{~h}$ in fasting animals. Then a stock diet (12 kcal) was introduced into the chamber and the measurement was continued for $6 \mathrm{~h}$. All measurements were performed at $25^{\circ} \mathrm{C}$.

Statistical analysis of body weight variations was performed by regression analysis of body weight as a function of time of the experiment. Minimum and mean oxygen consumption values were tested by one-way analysis of variance to determine differences among the groups studied. The thermal effect of food was tested by two-way analysis of variance to determine the differences among times and groups. The level of significance was set at $5 \%$.

Figure 1 shows the minimum and aver- 
age oxygen consumption. Minimum oxygen consumption corresponded to the average of two half-hour periods in which the oxygen consumption was minimum. The average oxygen consumption corresponded to the average of the whole 6 -h period of measurement. Neither recording showed significant differences among groups $(\mathrm{P}>0.05)$.

Figure 2 shows the cephalic thermal effect of feeding in the four groups studied. There was an increase in oxygen consumption after feeding the animals, followed by a return to initial values by the end of the measurement period $(\mathrm{P}<0.05)$. There were no significant differences among groups $(\mathrm{P}>0.05)$.

Colon interposition is one of several surgical treatments of short bowel syndrome. It allows an increase in intestinal transit and, in addition, the colon adapts to some functions of the small bowel $(7,10)$. It could be argued that the short bowel syndrome might reduce the oxygen consumption of animals subjected to strong small bowel resection, since the small bowel makes a significant contribution to whole body oxygen consumption.
Nevertheless, the results presented in this paper did not show any differences in resting oxygen consumption for intact and $80 \%$ intestinal resected rats 90 days after surgery. There were also no significant differences between resected animals and animals with colon interposition.

It could be argued that the utilization of female rats might interfere with oxygen consumption due to different estrous cycle phases. However, previous studies from this laboratory $(11,12)$ did not show any difference in oxygen consumption related to estrous cycle.

One of the consequences of the short bowel syndrome in humans is the weight loss associated with the gastrointestinal disturbances and malnutrition (13). Malnutrition and any kind of food restriction lead to lower oxygen consumption in animals $(12,14)$ and man (15). Since the animals in the present experiment did not lose body weight, we assume that their nutritional status was recovered after the surgical procedures. Even the animals in group III that were not subjected to bowel lengthening may have under-
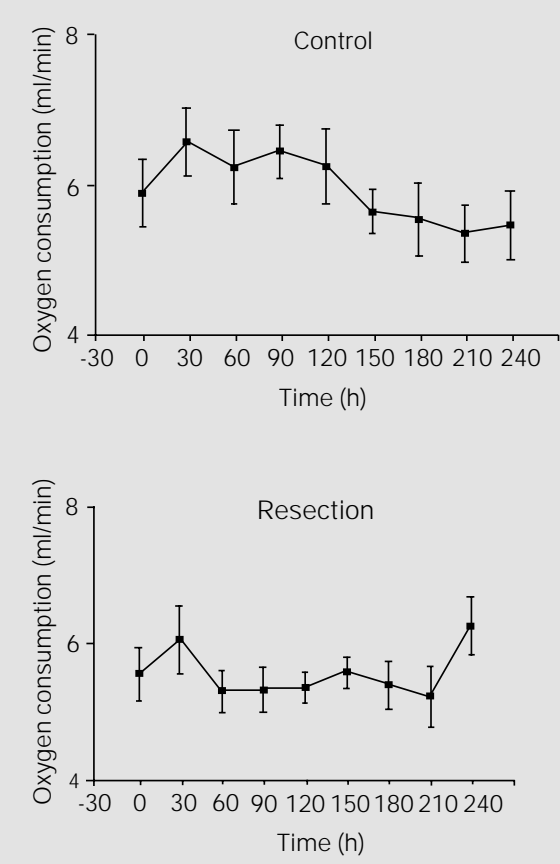
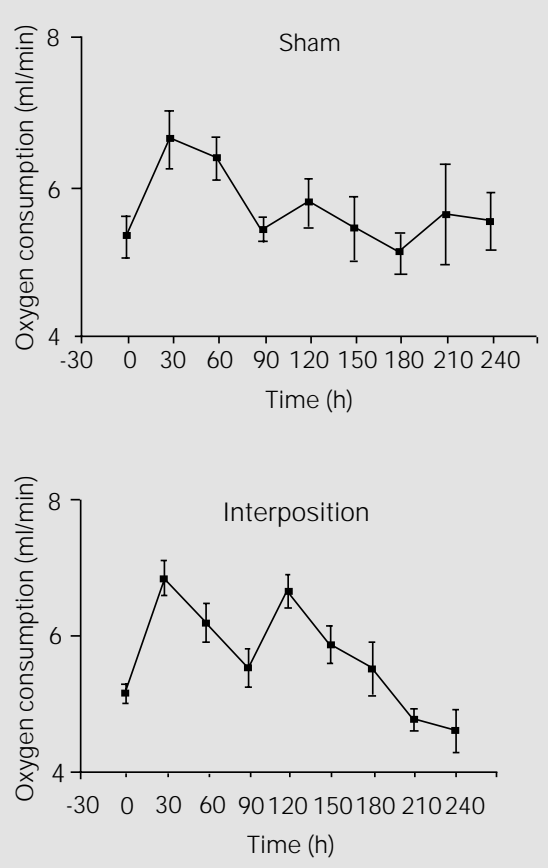

Figure 2 - Oxygen consumption measured before and for $4 \mathrm{~h}$ after a 12-kcal meal. There was a significant increase in oxygen consumption immediately after the meal, with a return to normal values at the end of the measurement period. 
gone adaptations that permitted them to keep a constant body weight. Some adaptation of the remnant bowel in short bowel syndrome has in fact been described (16). Short bowel syndrome elicited a substantial increase in intestinal surface area but glucose absorption per unit area decreased (17). In the present experiment, since the rats were probably not malnourished and were able to maintain their body weight, the oxygen consumption of all groups was similar and within the normal range expected for these animals. However, it is possible that some alterations could have been demonstrable sooner after the surgery procedures than the 90 days used here.

The cephalic thermal effect of food cor- responds to an increase of oxygen consumption soon after a meal and depends on the palatability of the meal (18) but not on meal size (19). The cephalic thermal effect of a 12 -kcal meal was clearly demonstrated in the present experiment (Figure 2). The four groups responded similarly to the test meal, which once more indicates that the short bowel syndrome permits adaptations in the rat so that its metabolic and nutritional status is not affected by the extensive shortening of the small bowel.

Thus, we conclude that the rat adapts very well to the short bowel syndrome so that its oxygen consumption and the cephalic thermal effect of food are not altered after massive small bowel resection.

\section{References}

1. Selzner M, IsenbergJ \& Keller HW (1996). Current status of surgical treatment of short bowel syndrome. Zentralblatt für Chirurgie, 121: 1-7.

2. Peng HC, Chen HC \& Wang CD (1994). Intestinal lengthening experience in shortbowel swine. Chung-Hua I Hsueh Tsa Chih, 54: 382-388.

3. Garcia VF, Templeton J M, Eichelberger MR, Koop CE \& Vinograd I (1981). Colon interposition for short bowel syndrome. J ournal of Pediatric Surgery, 16: 994-995.

4. Glick PL, Lorimier AA, Adzick NS \& Harrisson MR (1984). Colon interposition: an adjuvant operation for short gut syndrome. J ournal of Pediatric Surgery, 19: 719-725.

5. Brolin RE (1986). Colon interposition for extreme short bowel syndrome: a case report. Surgery, 100: 576-580.

6. Sidnu GS, Narasimharao KL, Rani VU, Sarkar AK, Chakravarti RN \& Mitra SK (1984). Morphological and functional changes in the gut after massive small bowel resection and colon interposition in rhesus monkeys. Digestion, 29: 47-54.

7. Plapler $H$, Fagundes DJ, Goldenberg S, Novo NF, J uliano Y \& Bekhor D (1992). Glucose absorption by the interposed colon segment after intestinal resection. Revista Española de Fisiologia, 48: 197-
201.

8. Foster DO \& Frydman ML (1979). Tissue distribution of cold-induced thermogenesis in conscious warm- or cold-acclimated rats reevaluated from changes in tissue blood flow: the dominant role of brown adipose tissue in the replacement of shivering and nonshivering thermogenesis. Canadian J ournal of Physiology and Pharmacology, 57: 257-270.

9. Frayn KN (1992). Studies of human adipose tissue in vivo. In: Kinney JM \& Tucker HN (Editors), Energy Metabolism: Tissue Determinants and Cellular Corollaries. Raven Press, New York, 267-298.

10. King DR, Anvari $M$, J amieson $G G \&$ King J M (1996). Does the colon adopt small bowel features in a small bowel environment? Australian and New Zealand J ournal of Surgery, 66: 543-546.

11. Luz J \& Griggio MA (1998). Effects of aging on the energy balance of pregnant rats. Annals of Nutrition and Metabolism, 42: 237-243.

12. Griggio MA, Luz J, Gorgulho AA \& Sucasas CM (1997). The influence of food restriction during different periods of pregnancy. International J ournal of Food Sciences and Nutrition, 48: 129-134.

13. Sacher P \& Stauffer UG (1997). An animal model for short-bowel syndrome in pig- lets to assess the efficiency of bowellengthening procedures. European J ournal of Pediatric Surgery, 7: 207-211.

14. Luz J \& Griggio MA (1991). Food restriction and refeeding in growing rats. J ournal of Comparative Biochemistry and Physiology, 99A: 477-480.

15. Grande F, Anderson JT \& Key A (1958) Changes of basal metabolic rate in man in semi-stanvation and refeeding. J ournal of Applied Physiology, 12: 230-238.

16. Ziegler TR, Mantell MP, Chow J C, Rombeau J L \& Smith RJ (1996). Gut adaptation and the insulin-like growth factor system regulation by glutamine and IGF-I administration. American J ournal of Physiology, 271: G866-G875.

17. Kawaguchi AL, Dunn JC, Lam M, O'Connor TP, Diamond J \& Fonkalsrud EW (1998). Glucose uptake in dilated small intestine. J ournal of Pediatric Surgery, 33: 1670-1673.

18. Diamond P, Brondel L \& LeBlanc J (1985). Palatability and postprandial thermogenesis in dogs. American J ournal of Physiology, 248: E75-E79.

19. LeBlanc J \& Diamond P (1986). Effect of meal size and frequency on postprandial thermogenesis in dogs. American J ournal of Physiology, 250: E144-E147. 